\title{
Modifikasi Desain, Produksi, \& Pemasaran Pakaian Bersama Lpk Nadya Jaya \& Lovadova
}

\author{
Susi Hartanto ${ }^{1}$ \\ ${ }^{1}$ Universitas Pelita Harapan \\ susi.fdtp@uph.edu
}

\begin{abstract}
Abstrak
Permasalahan klasik PkM adalah PkM hanya berhenti sampai pelatihan dan sulit diteruskan ke tahap lebih lanjut karena banyak kendala seperti modal, SDM, produksi, pemasaran, dan lainnya. Untuk itu, PkM kali ini menggandeng mitra brand untuk membantu produksi dan pemasaran produk PkM. Melalui periode PkM sebelumnya, mitra PkM telah melihat manfaat pola digital yang praktis dan presisi. Dukungan dari mitra brand juga mulai terjalin sehingga terbentuk siklus utuh dari membuat hingga menjual. Desain pakaian yang berkembang terus dan tuntutan mitra brand yang selalu ingin produk baru membuat pelaku industri termasuk mitra harus terus belajar meningkatkan kemampuan membuat pola pakaian yang lebih kompleks dan beragam mengikuti tren. Periode ini juga memberikan pelatihan bahwa pola tidak harus menyontek $100 \%$, melainkan bisa dimodifikasi sesuai ide, bahan dan aksesoris yang tersedia, batasan harga, dan lainnya. Dalam hal ini, mitra PkM mengikuti arahan mitra brand sebagai klien. Hasil PkM periode ini berupa pola digital dan sample pakaian diteruskan ke mitra brand untuk diproduksi dan dipasarkan. Pelatihan ini merupakan tahapan ketiga dari rangkaian PkM yang disusun dalam skema 3 tahun. Tahapan ketiga ini dibagi menjadi 2 rangkaian proses yang berjalan beriringan agar selaras dengan proses industri fesyen yang cepat.
\end{abstract}

Kata Kunci: sample, pola, digital, pakaian, produksi

\section{PENDAHULUAN}

PkM ini terbagi menjadi 2 pekerjaan:

1) memberikan pelatihan lanjutan untuk membuat pola digital pakaian yang lebih kompleks dari referensi foto.

Disini mitra PkM diajak lebih berimajinasi memodifikasi desain berdasarkan referensi foto seadanya. Seringkali referensi tidak bisa dibuat apa adanya, karena ada ketidakcocokan bahan, aksesoris, detail, ukuran, warna, dan lainnya. Sehingga perlu ilmu modifikasi.

Disini juga perlu adanya informasi tentang mitra brand seperti: konsep brand, jenis dan ukuran pakaian yang dijual, standar ukuran sample, produk/ kategori bestseller, positioning harga ritel, dan lainnya. Hal ini agar mitra PKM dan UPH samasama bisa mengembangkan pola \& sample yang cocok dengan mitra brand.
2) Memproduksi, membuat konten, dan memasarkan produk secara online lewat kerjasama dengan mitra brand. Tujuan utama periode B bukanlah untuk mendapat profit, melainkan mendapat input mitra brand akan pola dan sample yang dihasilkan, apakah polanya jelas/ mudah dimengerti/ mudah diproduksi; serta mendapat input pasar akan produk yang dihasilkan.

PkM ini dibagi menjadi 2 rangkaian proses yang berjalan bersamaan untuk mengikuti fase industri fesyen yang cepat. Standar umum untuk produk slow fashion dalam merilis produk baru adalah per musim (per 3 bulan). Untuk produk fast fashion bisa dalam hitungan 1-4 minggu sudah merilis produk baru. PkM ini juga akan mengulang sedikit dari PkM periode sebelumnya dalam hal memberikan update informasi terbaru mengenai

$$
\text { Pendidikan }
$$


fesyen. Hal ini dikarenakan selalu ada yang baru dalam dunia fesyen setiap harinya. Dalam periode ini juga akan ada sesi pengingat mengenai rencana 3 tahun, berikut ulasan PkM periode sebelumnya.

\section{Permasalahan Mitra PkM}

LPK Nadya Jaya merupakan lembaga kursus jahit rumahan di daerah perkampungan Duri Kosambi, Jakarta Barat. LPK ini dikelola oleh sepasang suami istri, Pak Maulana dan Ibu Sri sejak beberapa tahun silam. Pak Maulana bertugas mengelola keuangan dan segala keperluan lainnya, sedangkan Ibu Sri fokus memberikan pengajaran.

Selain memberikan kursus, LPK ini juga menerima pesanan jahitan, namun dalam kuantitas butik atau kecil (dalam jumlah satuan atau puluhan). Pekerjaan membuat pola dan menjahit utama tetap dikerjakan oleh bu Sri seorang.

Berikut rangkuman permasalahan mitra: 1) Mitra belum pernah mengenal pola digital yang sudah umum dipakai di luar negeri; 2) Mitra sering telat mengerjakan pesanan sehingga menimbulkan tertundanya workflow bisnis fesyen yang biasa sangat musiman; 3) Semua pembuatan pola untuk bahan ajar dan pekerjaan pesanan masih menggunakan cara manual (dengan pensil dan kertas) sehingga tidak ada data jika kertas pola hilang, dan semua pola harus diulang dari awal jika ada revisi; 4) Ada language gap antara mitra dengan klien untuk istilah-istilah fesyen; 5) Pembuatan sample yang selalu telat dan kurang rapih

Pada periode sebelumnya, semua permasalahan ini sudah mulai diselesaikan perlahan bersama melalui penyuluhan informasi fesyen dan studi kasus pembuatan pola digital. Namun etos kerja yang selalu sering telat dengan berbagai alasan ini yang agak susah diperbaiki.

\section{Mitra Brand}

PkM ini bekerja sama dengan brand pakaian Lovadova. Lovadova adalah brand pakaian yang dirintis pada 2013 di Vietnam dengan konsep menggunakan kain sisa dari industri fast fashion (remnant fabrics), dengan kapasitas produksi 400500 pes per bulan. Model pakaiannya bersifat kasual, berukuran one size, untuk peruntukan wanita 20-30an. Lovadova memiliki cabang di Vietnam dan Indonesia. Vietnam diperuntukkan untuk produksi, $\mathrm{R} \& \mathrm{D}$, dan penjualan; Indonesia diperuntukkan untuk penjualan, branding, dan R\&D. Harga ritel (apabila dikonversikan dari VND ke IDR) berkisar antara Rp 199.000 hingga Rp349.000,-.

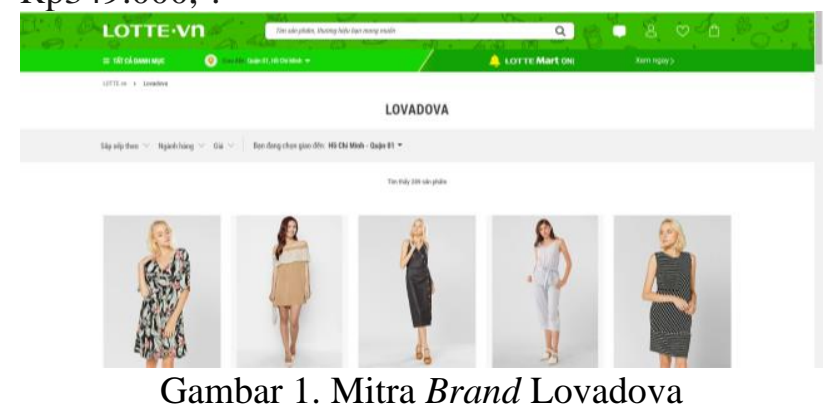

Lovadova Vietnam dijual di berbagai platform e-commerce seperti Lotte, Adayroi, Shopee, dan Yes24. Lovadova Indonesia tersedia di platform e-commerce Bobobobo, Zalora, Zilingo, ilotte, Tokopedia, dan Shopee.

Kedua cabang Lovadova memang samasama melakukan penjualan, namun untuk saat ini, produksi hanya dilakukan di Vietnam. Sehingga mitra PkM lebih cocok bekerja sama dengan Lovadova Vietnam.

Secara kategori produk, Lovadova menjual sekitar 50\% dress, $10 \%$ atasan, 10\% bawahan, $10 \%$ playsuit/ jumpsuit/two-piece, $10 \%$ produk lainnya (lingerie, luaran). Sehingga produksi akan lebih ditujukan untuk produk dress sebagai kategori utama.

Untuk PkM ini, Lovadova Vietnam berperan menerima pola dan sample hasil tim PkM, membuat ulang sample tersebut sesuai stock kain yang tersedia agar cocok untuk diproduksi. Hasil sample yang diterima dari mitra PkM akan disesuaikan dengan standar ukuran onesize yang biasa diproduksi disana. Perlahan, mitra PkM akan harus butuh menyesuaikan pola agar lebih sesuai dengan pangkalan data Lovadova Vietnam. Pangkalan data terutama dalam hal ukuran, dan menggunakan referensi pola untuk produk bestseller. Tujuannya, agar sample tidak butuh banyak revisi.

Sehubungan dengan konten PkM ini, Lovadova Vietnam juga akan memberikan ulasan, kritik, saran atas hasil pola dan sample yang dihasilkan, agar di kemudian hari ada revisi dan pengembangan produk yang lebih baik dan sesuai

$$
\text { Pendidikan }
$$


standar industri pakaian. Adapun penyesuaian dari sample ke produk jadi merupakan pembelajaran penting bagi mitra PkM akan bagaimana memenuhi permintaan klien bisnis.

Untuk periode PkM ini, Lovadova Vietnam berperan membantu produksi dari sample yang telah dihasilkan untuk kuantitas $1 *$ SKU $=5$ pcs sebagai produk untuk tes pasar. Umumnya dalam industri pakaian, 1 *SKU bisa diproduksi minimal 50 pcs hingga ribuan pcs. Sesuai prinsip economies of scale, semakin banyak kuantitas yang diproduksi, maka harganya semakin murah. Untuk jumlah yang hanya 5 pcs, harga dan kualitas produksi Lovadova sangat kompetitif dibandingkan bila dikerjakan di Jakarta. Hasil produksi kemudian diteruskan untuk foto katalog dan pembuatan konten agar bisa dijual sesuai standar platform online.

*Stock Keeping Unit

Sehubungan dengan konten PkM ini, Lovadova Vietnam juga akan memberikan ulasan, kritik, saran atas hasil pola dan sample yang diproduksi, agar di kemudian hari ada revisi dan pengembangan produk yang lebih baik dan sesuai standar industri pakaian. Adapun penyesuaian dari sample ke produk jadi merupakan pembelajaran penting bagi mitra PkM akan bagaimana memenuhi permintaan klien bisnis. Adapun hasil penjualan atas produk yang sama-sama dihasilkan mitra PkM juga memberikan refleksi akan daya saing mitra PkM di industri pakaian.

\section{METODE}

PkM ini adalah PkM penerapan teknologi menggunakan program Rhinoceros yang dilaksanakan melalui banyak studi kasus pembuatan pola pakaian, dan pembekalan ilmu mengenai seluk beluk bisnis pakaian di Indonesia.

Minggu 1: memberikan update tren fesyen dunia dan Indonesia (khususnya fast fashion) \& kalender pemasaran e-commerce fesyen Indonesia; mendapat dan menyampaikan ulasan mitra brand hasil PkM periode 2; diskusi upaya lanjutan atas hasil ulasan

Minggu 2-6: studi kasus membuat pola digital untuk 4 pakaian yang lebih kompleks dalam versi A0 dan A4

Minggu 7: ke pasar Cipadu untuk membeli kain dan aksesoris

Minggu 8-12: menjahit sample dari 5 pola yang telah dibuat
Minggu 13-14: merevisi, membongkar sample dan pola

Minggu 15: mengirimkan pola \& sample ke mitra brand

Minggu 16: mitra brand menerima hasil pola \& sample dari mitra $\mathrm{PkM}$

Minggu 17-21: mempelajari pola \& sample, revisi, membuat ulang sesuai standar sample produksi mitra brand

Minggu 21-22: merevisi sample dan pola

Minggu 23: mengirimkan pola \& sample ke mitra brand

Minggu 22-23: produksi

Minggu 24: foto katalog

Minggu 25: menerima hasil foto, revisi foto bila ada, membuat konten

Minggu 26-27: upload - produk live

Minggu 28: review sementara, closing periode 3

\section{HASIL DAN PEMBAHASAN}

Minggu 1: memberikan update tren fesyen dunia dan Indonesia (khususnya fast fashion) \& kalender pemasaran e-commerce fesyen Indonesia; mendapat dan menyampaikan ulasan mitra brand hasil PkM periode 1 dan 2; diskusi upaya lanjutan atas hasil ulasan. Berikut hasil review untuk produk yang sudah dihasilkan di periode sebelumnya.
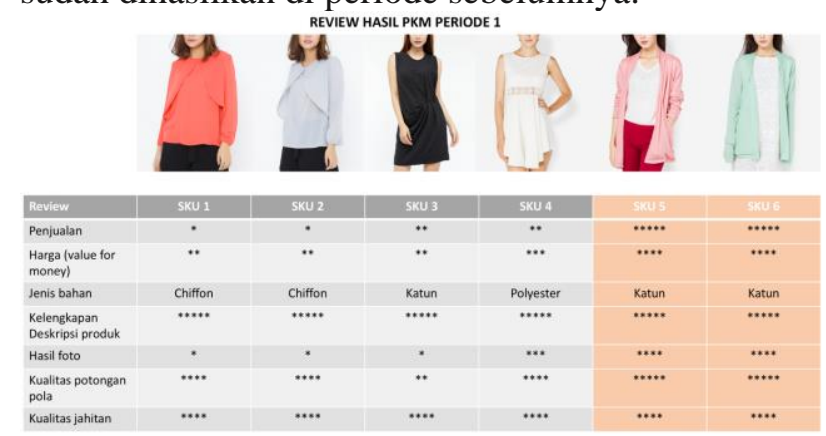

Gambar 2. Review Hasil Produk PKM Periode 1

Dijelaskan kepada mitra pkm bahwa, ada banyak sekali faktor yang mempengaruhi penjualan online sebuah produk pakaian, seperti:

\section{1) Stok per sku \& histori penjualan}

Setiap platform e-commerce pasti menginginkan produk yang deep stock (stok banyak), terlebih pada platform marketplace yang menjual segala jenis produk seperti Tokopedia dan Shopee. Produk dengan stock banyak akan lebih diprioritaskan untuk segala macam promosi. Produk dengan

$$
\text { Pendidikan }
$$


histori penjualan yang baik (telah dibeli oleh 1,536 pengguna misalkan) pastinya meninggalkan impresi yang baik bagi calon pembeli.

Contohnya seperti produk Tokopedia, apabila sudah terjadi 6,271 transaksi, pastinya produk terjamin lebih diminati konsumen dibanding produk yang transaksinya masih 0 . Untuk kasus mitra brand, stok agak susah dibuat banyak berhubung konsep brand menggunakan remnant fabrics (kain sisa), sehingga memang stok hanya berkisar biasanya antara 5-30 pcs per sku. Jumlah stok itu memang bisa menjadi kelebihan sekaligus kekurangan. Untuk itu, brand lebih cocok dijual pada platform yang memang mengkhususkan fesyen sebagai segmen utama, agar lebih visible, misalkan seperti Zalora atau Zilingo.

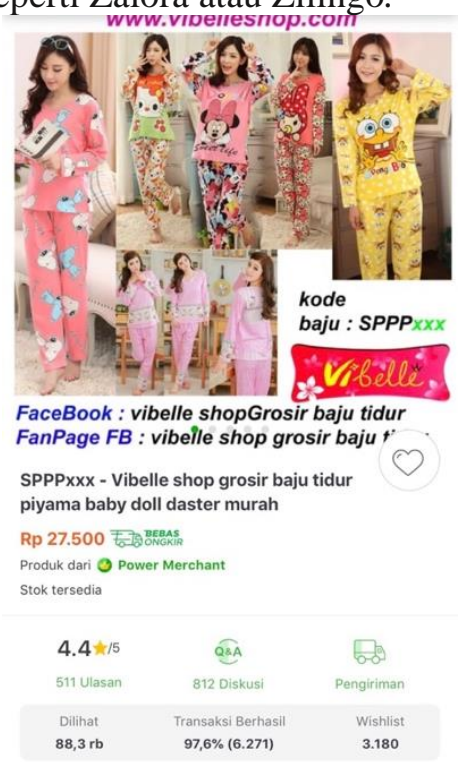

Gambar 3. Contoh SKU dengan stok melimpah

\section{2) Harga}

Harga mahal, murah, atau pantas memang sifatnya relatif. Banyak sekali aspek yang mempengaruhi penilaian harga atas suatu produk pakaian, misalkan jenis dan kualitas bahan, kualitas jahitan, hasil foto, brand value, dan sebagainya. Dalam online, ada yang disebut sebagai shopping cart (add to cart). Price per cart spent yang biasa dikeluarkan oleh konsumen Zalora paling banyak berkisar pada Rp 250.000,- ke bawah. Sudah umumnya, harga murah biasanya lebih diminati dibandingkan harga mahal. Dalam kasus mitra brand Lovadova, harga rata-rata berkisar antara Rp 229.900 hingga Rp 349.900,-., sehingga masih dalam kisaran yang sama dengan price per cart spent konsumen Zalora

\section{3) Jenis bahan}

Produk pakaian memang ada kalanya susah dinilai sebelum dipegang, terutama bagi konsumen yang tidak mengenal jenis-jenis kain. Apalagi teknologi kain semakin canggih, ada ribuan varian dengan kandungan persentase bahan yang berbeda-beda, yang susah dinilai sebelum dipegang. Melalui pembelian online pun, konsumen biasanya memiliki garansi retur apabila tidak puas dengan produk yang dibeli. Sehingga secantik apapun fotonya, apabila konsumen tidak cocok atau suka dengan jenis bahan produk, retur sangat bisa terjadi. Dalam kasus mitra brand Lovadova, jenis kain dideskripsikan hanya sebatas jenis nama komersialnya (katun rayon, chiffon, denim, scuba, dan lainnya), namun tidak dalam bentuk persentase kandungan. Berhubung suplai kain adalah sisa kain yang dikumpulkan di gudang kain, sehingga tidak bisa diketahui asal usul dan persentase kandungan yang sebenarnya. Namun, konsumen pada umumnya hanya bisa membedakan beberapa jenis kain komersial yang populer. Konsumen tidak mungkin bisa membayangkan tekstur kainnya walaupun disebutkan sedetail mungkin persentasenya. Hanya ahli kain/ manufaktur kain yang kemungkinan bisa membedakan kain dari sisi persentase.

\section{4) Kelengkapan deskripsi produk}

Deskripsi produk meliputi semua deskripsi yang menjelaskan bahan (katun, polyester, spandex, linen, chiffon, dan sebagainya), kandungan bahan (misalkan $80 \%$ polyester, 20\% spandex), ukuran produk (termasuk lingkar dada, lingkar pinggang, lingkar pinggul, panjang, panjang lengan, dan sebagainya), ukuran model (tinggi dan berat badan, lingkar dada, lingkar pinggang, lingkar pinggul), detail pakaian (resleting jepang, dan sebagainya), jenis pakaian (pleated maxi skirt), gaya pakaian (bohemian, chic, vintage, dan sebagainya). Semua deskripsi biasanya terdiri dari 3-5 deskripsi agar produk mudah dinilai. Semakin lengkap deskripsi, semakin mudah bagi konsumen untuk menilai; dan sebaliknya. Dalam standar Zalora pun, setidaknya harus ada 3-4 deskripsi yang ditulis; deskripsi yang kurang dari itu akan ditolak oleh QC karena dianggap tidak lengkap dan tidak jelas.

$$
\text { Pendidikan }
$$




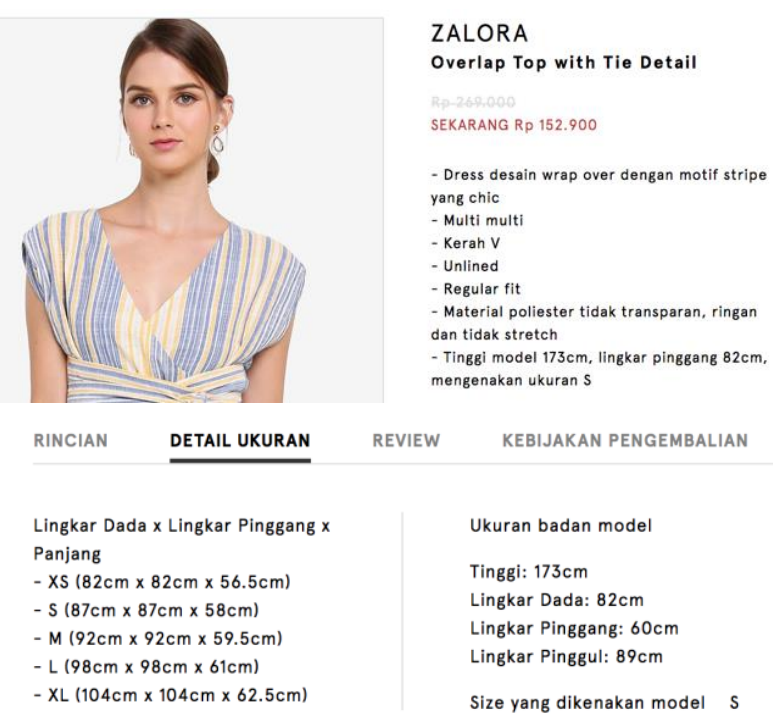

Gambar 4. Contoh Deskripsi Produk (Gaya \& Ukuran)

\section{5) Hasil foto}

Hasil foto disini termasuk paras model, kebangsaan model (paras bule/Asia/eksotis), body language, kualitas foto, kualitas editing, styling pakaian, pemaduan aksesoris, dan berat file.

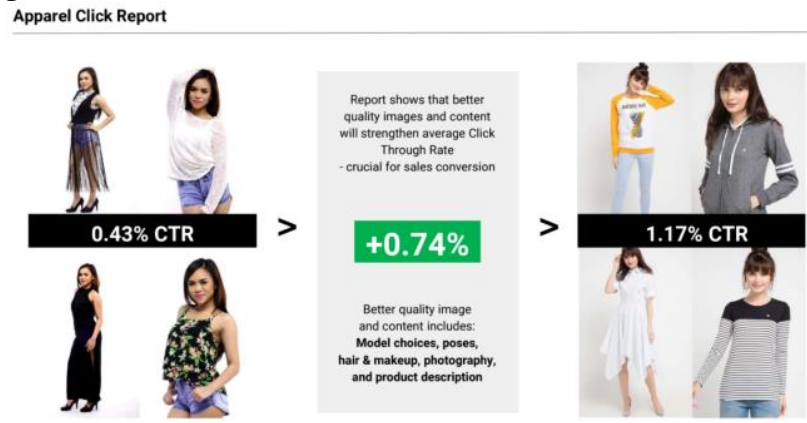

Gambar 5. Perbandingan Hasil Foto terhadap Click Through Rate (CTR)

Foto dengan model yang berpenampilan tidak menarik memiliki CTR (Click Through Rate) yang rendah, dan sebaliknya. Mayoritas brand di Indonesia biasanya menggunakan model luar karena dinilai lebih menarik secara fisik. Model luar saja pun tidak menjadi jaminan foto akan terlihat menarik, karena keluwesan berfoto, pengalaman (portfolio), body language sangat menentukan bagus tidaknya sebuah foto. Apalagi untuk foto produk pakaian dalam atau olahraga, model biasanya diharuskan memiliki badan yang cukup baik dan atletis agar bisa menjual produk dengan baik. Peran stylist disini pun sangat penting untuk memadumadankan jenis baju, riasan muka dan rambut, alas kaki, dan aksesoris agar foto tampil maksimal, mendukung produk yang dijual. File foto yang diunggah ke platform penjualan memang berbeda tergantung kebijakan masing-masing platform, namun umumnya sebaiknya berkisar antara 200-500kb, karena kualitas gambarnya sudah cukup untuk dibuka, baik melalui hp maupun desktop. File yang terlalu besar dan berat akan susah dibuka bagi konsumen yang akses internetnya kurang baik. Dalam kasus mitra brand Lovadova, kualitas foto dinilai bisa diterima.

Semua komponen di atas pun harus selaras dengan brand image yang ingin ditawarkan kepada konsumen. Dari ketiga brand ini (lovebonito, shopfru, pomelo), bisa dilihat bahwa semua foto memperlihatkan brand image yang berbeda-beda. Lovebonito menjual image wanita mapan yang feminis. Shopfru menjual image wanita yang minimalis dan indie. Pomelo menjual image wanita yang ceria dan penuh warna. Konsumen juga semakin pintar menilai, sehingga foto dituntut lebih maksimal, baik secara catalog maupun lookbook.

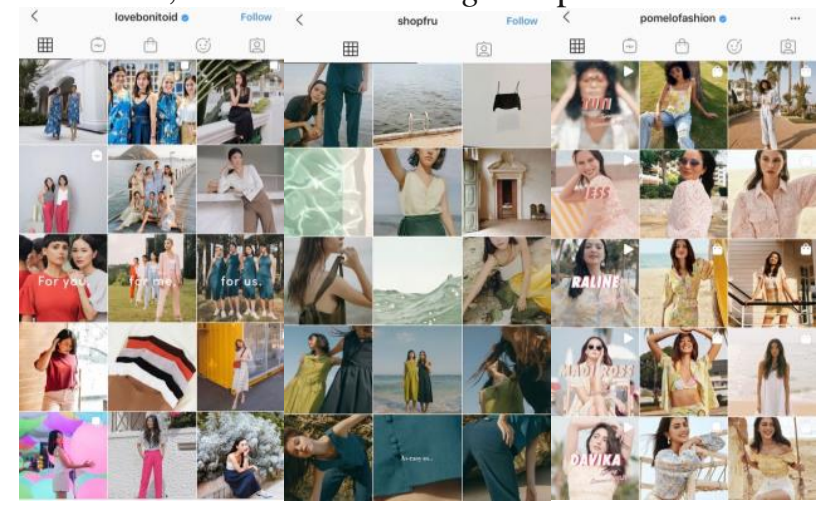

Gambar 6. Contoh Foto dengan Brand Image yang Berbeda

\section{6) Kualitas potongan pola}

Potongan baju juga salah satu yang susah diukur sebelum dikenakan. Karena nyaman tidaknya sebuah baju dipakai tidak bisa dinilai dari foto. Konsumen juga biasanya memiliki garansi retur 730 hari (tergantung kebijakan platform) apabila baju dirasa terlalu besar, terlalu kecil, atau kurang nyaman dipakai. Untuk hasil produksi mitra brand Lovadova, kualitas potongan pola dirasa baik untuk produk dress, celana, jumpsuit. Namun, untuk 
produk atasan (kemeja, blouse) dirasa masih kurang maksimal, terutama di daerah lengan dan kerah.

\section{7) Kualitas jahitan}

Sama halnya juga, konsumen bisa dengan mudah meretur produk apabila kualitas jahitan dirasa tidak baik, atau apabila ada jahitan lepas/tidak rapih (dianggap produk cacat), atau kualitas dinilai tidak sesuai harganya. Untuk harga jual produk Lovadova, kualitas jahitan dinilai sepadan dengan harganya.

\section{8) Promo, diskon, voucher, endorsement}
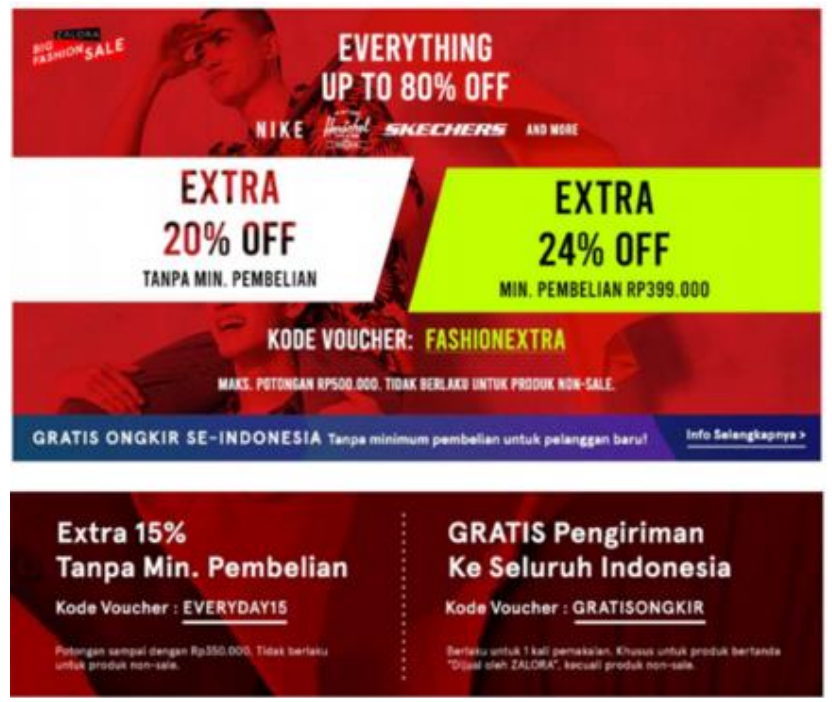

Vouchers Benefit: Direct Impact To Sales Help to drive up exposure of brand's assortment and conversion rate, which will led to brand's sales growth
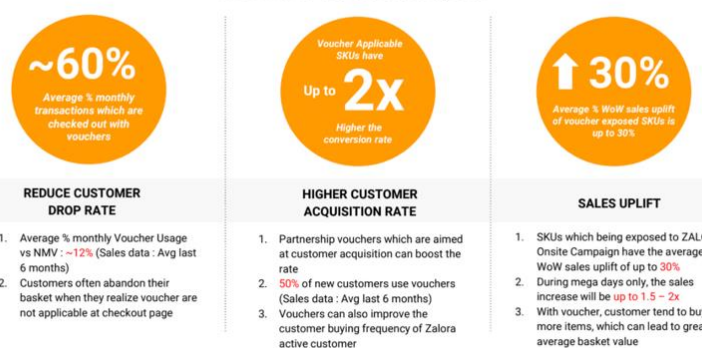

SALES UPLIFT

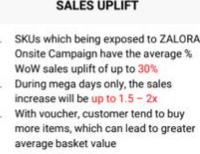

ZALORA

Gambar 7. Ilustrasi Keuntungan menggunakan Promo Voucher

Hal yang satu ini bisa dibilang paling berpengaruh pada penjualan. Ada banyak sekali bentuk promosi yang bisa dilakukan untuk menjual sebuah produk. Belakangan, penjual banyak ditawarkan untuk mengikuti voucher campaign untuk meningkatkan penjualan. Berdasarkan data, voucher bisa meningkatkan hingga 30\% dan bahkan 1.5-2 kali lipat saat mega days (11.11 atau 12.12).

Endorsement melalui celebgram juga marak dilakukan karena konsumen saat ini adalah kaum milenial yang memiliki segala macam akses digital.

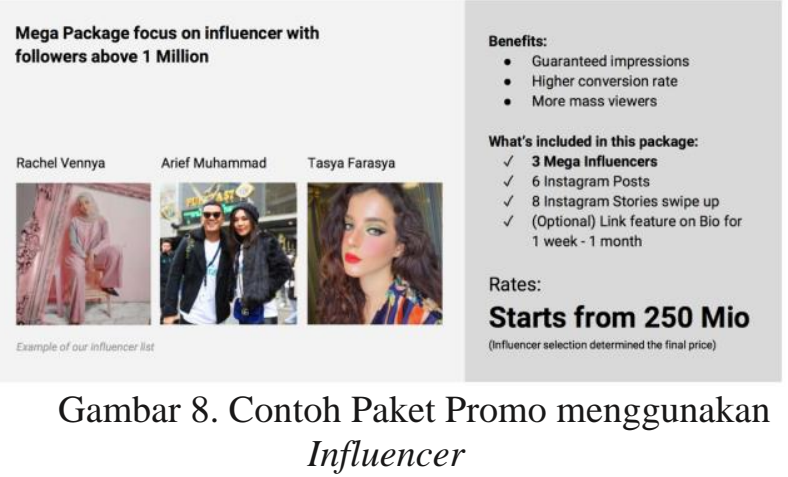

Namun kembali lagi, semua bentuk promosi mudah dilakukan jika ada dana.

\section{9) SEO (Search Engine Optimization)}

Dalam penjualan digital, iklan bisa dijalankan melalui mesin pencari utama yang paling banyak digunakan konsumen (Google). Ada tidaknya wujud/iklan brand dalam google bisa menjadi penentu apakah brand mudah diakses atau tidak oleh konsumen. Dalam hal Lovadova, brand tidak mengalokasikan budget khusus SEO.

\section{0) Popularitas brand di media social}

Keaktifan dan engagement brand dalam media sosial (Instagram misalkan) merupakan faktor penentu juga atas penjualan yang terjadi di berbagai platform penjualan. Brand yang memiliki banyak follower aktif (bukan pasif) pastinya akan lebih mudah menjual produknya kepada konsumen, dan sebaliknya. Sayangnya dalam kasus mitra brand Lovadova, brand belum seaktif brand lainnya, dan engangement terhadap follower dan sebaliknya cenderung rendah.

\section{1) Popularitas platform penjualan di mata konsumen}

Popularitas platform disini termasuk promo yang diberikan, garansi retur, bebas ongkir, kualitas layanan pelanggan, brand value, dan sebagainya. Semakin baik sebuah platform di mata konsumen, maka semakin tinggi kesempatan menjual. Umumnya popularitas sangat bergantung pada besarnya dukungan diskon yang diberikan oleh 
platform. Saat ini semua unicorn berlomba-lomba menyuntik dana untuk memberikan perang diskon kepada konsumen. Akhirnya sudah bisa dipastikan, pasti platform dengan dana terbesar dan promo terbesar yang paling bertahan dan populer di mata konsumen.

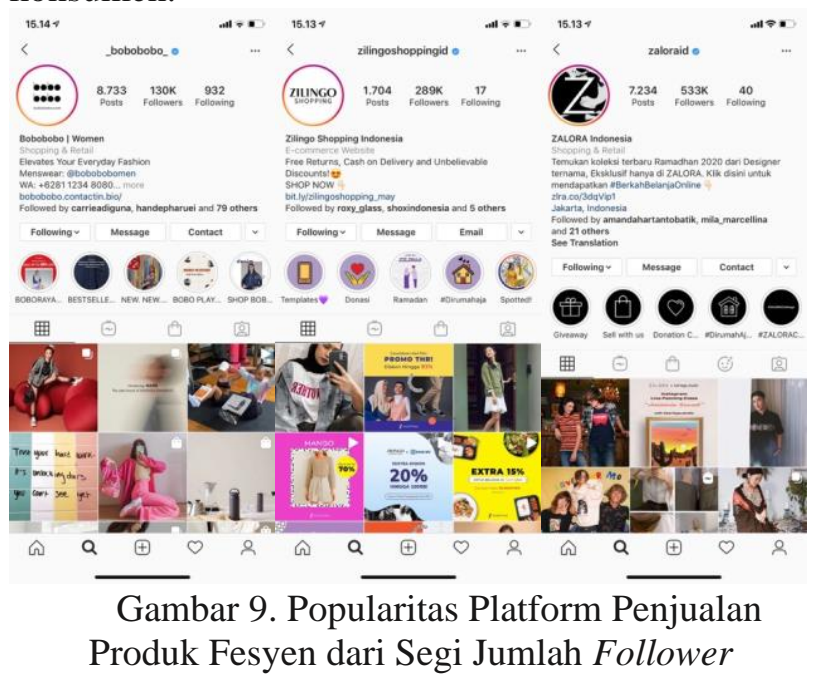

Berikut beberapa contoh platform penjualan produk fesyen di Indonesia, berurut dari yang follower-nya paling sedikit hingga yang paling besar.

\section{2) Ada tidaknya toko fisik}

Ada tidaknya toko fisik (di mall, ataupun di area lain) menjadi bukti autentik bahwa brand pakaian adalah penjual asli. Belakangan hal ini tidak terlalu menjadi pengaruh karena online sudah berpenetrasi baik. Namun, toko fisik menjadi lebih penting saat ini apabila brand menawarkan jasa yang sifatnya custom, atau yang produk yang harganya premium (misal 1 dress berharga Rp 20 juta). Sehingga, ada lokasi dimana customer bisa mencoba terlebih dahulu. Dalam kasus mitra brand Lovadova, ada workshop yang berlokasi di distrik 5, Ho Chi Minh, Vietnam. Sehingga dalam hal ini, walaupun tidak ada toko yang cantik di mall, konsumen yang merasa ragu bisa saja mendatangi workshop agar lebih yakin membeli online.

\section{3) Faktor keberlanjutan}

Isu berkelanjutan menjadi lebih marak belakangan terutama bagi para milenial yang lebih peduli lingkungan. Sehingga, banyak brand yang mengusung konsep berkelanjutan sebagai salah satu core value brand yang dijual. Brand-brand yang bersifat fast fashion seperti H\&M ataupun Forever 21 (walaupun dijual murah), belakangan kurang diminati karena dianggap tidak melestarikan lingkungan. Mitra brand Lovadova sejak awal merintis bisnis dengan konsep menggunakan remnant fabrics (kain sisa pabrik) sehingga sudah memiliki nilai plus dalam faktor keberlanjutan.

Update informasi ini yang disampaikan kepada mitra PkM untuk menambah wawasan. Informasi dibatasi agar mudah dicerna.

Minggu 2-6: studi kasus membuat pola digital untuk 4 pakaian yang lebih kompleks dalam versi A0 dan A4

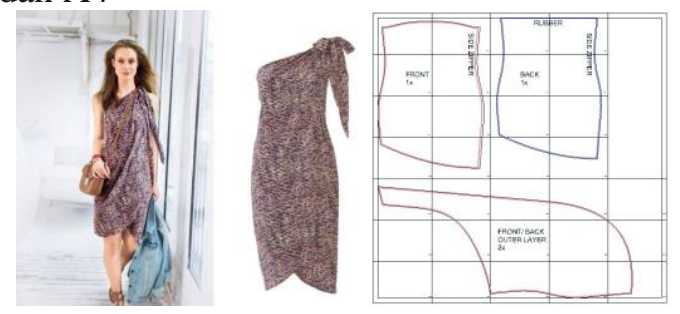

Gambar 10. Referensi \& Hasil Pola 1

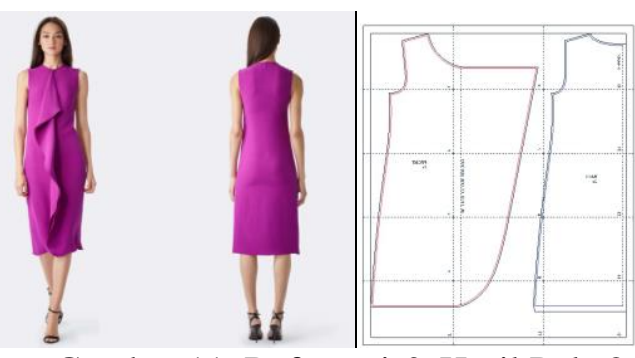

Gambar 11. Referensi \& Hasil Pola 2

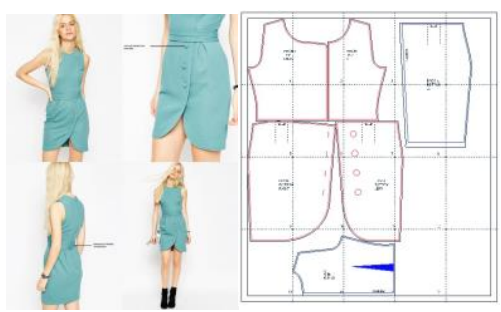

Gambar 12. Referensi \& Hasil Pola 3

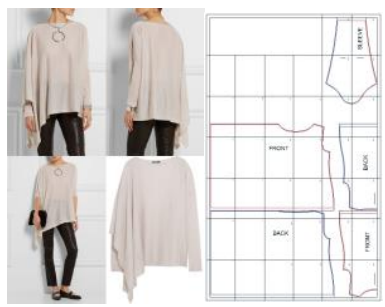

Gambar 13. Referensi \& Hasil Pola 4

Pendidikan 
Minggu 7: ke pasar Cipadu untuk membeli kain dan aksesoris

Minggu 8-12: menjahit sample dari 5 pola yang telah dibuat

Minggu 13-14: merevisi, membongkar sample dan pola

Minggu 15: mengirimkan pola \& sample ke mitra brand

Minggu 16: mitra brand menerima hasil pola \& sample dari mitra $\mathrm{PkM}$

Minggu 17-21: mempelajari pola \& sample, revisi, membuat ulang sesuai standar sample produksi mitra brand

Minggu 21-22: merevisi sample dan pola

Minggu 23: mengirimkan pola \& sample ke mitra brand

Minggu 22-23: produksi

Minggu 24: foto katalog

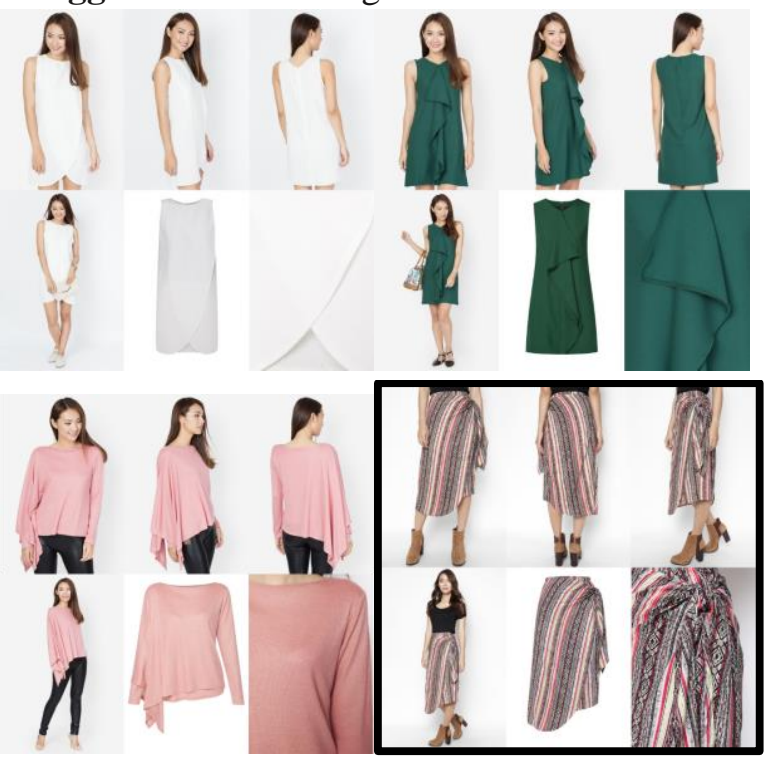

Gambar 14. Hasil Foto Katalog 4 Sample

Ada kesalahan foto untuk produk 4 (seharusnya dress, tetapi difoto sebagai rok), sehingga perlu revisi terlebih dulu.

Minggu 25: menerima hasil foto, revisi foto bila ada, membuat konten

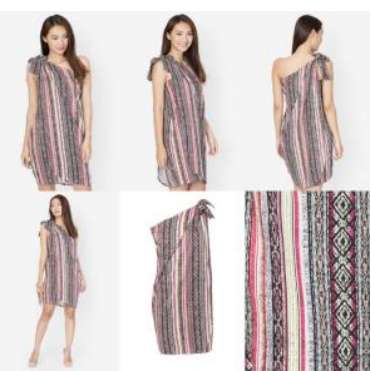

Gambar 15. Hasil Revisi Foto Katalog

Minggu 26-27: upload - produk live

Minggu 28: review sementara, closing periode PkM

Ada 4 pola baju digital yang dihasilkan pada periode 3 berikut foto katalog dan stock masing-masing 5 pcs untuk coba dijual. Berikut review perbandingan antara referensi vs produk jadi.

Tabel 1. Hasil PkM

\begin{tabular}{|c|c|c|}
\hline Referensi & Produk Jadi & Sisi Modifikasi \\
\hline & & $\begin{array}{l}\text { Tidak ada kain } \\
\text { yang sama persis, kain } \\
\text { mengikuti stock kain } \\
\text { mitra brand } \\
\text { Dipilih kain yang } \\
\text { motifnya ramai, non } \\
\text { elastis, dan ringan mirip } \\
\text { seperti referensi } \\
\text { Ikatan bisa di } \\
\text { kanan atau kiri, tidak } \\
\text { menjadi masalah }\end{array}$ \\
\hline & & $\begin{array}{l}\text { Tidak ada kain yang sama } \\
\text { persis, kain mengikuti stock kain } \\
\text { mitra brand } \\
\text { Dipilih kain yang } \\
\text { motifnya polos, sedikit elastis, } \\
\text { dan agak berat mirip seperti } \\
\text { referensi. } \\
\text { Dipilih kain yang } \\
\text { premium, karena potongan pola } \\
\text { terlihat baik dan rapih } \\
\text { Dibuat mini dress agar } \\
\text { harga produksi lebih murah } \\
\text { Dibuat resleting belakang, } \\
\text { bukan resleting samping seperti } \\
\text { referensi karena tidak ada stock } \\
\text { resleting samping (resleting } \\
\text { jepang) }\end{array}$ \\
\hline & & $\begin{array}{l}\text { Tidak ada kain yang sama } \\
\text { persis, kain mengikuti stock kain } \\
\text { mitra brand } \\
\text { Dipilih kain yang } \\
\text { motifnya polos, non elastis, } \\
\text { seperti referensi } \\
\text { Dibuat agak longgar } \\
\text { berhubung mitra brand hanya } \\
\text { memproduksi ukuran one size. } \\
\text { Dikhawatirkan jika terlalu } \\
\text { bodyfit seperti referensi, akan } \\
\text { lebih susah dijual. } \\
\text { Tidak menggunakan } \\
\text { kancing dan belt agar harga } \\
\text { produksi lebih murah }\end{array}$ \\
\hline
\end{tabular}




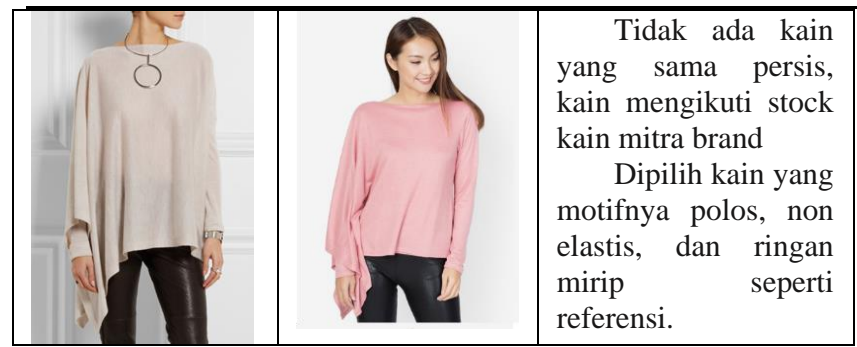

Dari tabel ini, mitra PkM bisa melihat dengan jelas bahwa modifikasi sangat mudah dilakukan, dan sulit dihindari. Hal ini terutama karena stock kain remnant mitra brand yang tidak pernah bisa diprediksi, sehingga hampir $0 \%$ kemungkinan menggunakan bahan yang sama dengan referensi. Selain itu, mitra PkM juga harus mempertimbangkan bahwa mitra brand hanya menjual 1 ukuran, yaitu one size. Sehingga pakaian tipe longgar akan lebih mudah dijual dibanding pakaian ketat (bodyfit). Sehingga referensi apapun yang terlihat ketat, sebaiknya diperbesar agar cocok dengan karakter produk yang dijual mitra brand. Dari sisi biaya produksi, biaya kain adalah komponen kedua terbesar setelah ongkos jahit. Sehingga pengurangan kain akan pastinya berdampak pada biaya. Pastinya biaya memproduksi midi dress akan lebih tinggi dibandingkan mini dress. Memang tidak harus semua dress dijadikan potongan pendek, keputusan ini melihat model pakaian, dan stock kain yang tersedia. Keputusan menggunakan kain premium ataupun kain biasa tergantung dari hasil sample, potongan pola, dan model pakaian yang dibuat. Apabila sample sudah terlihat indah, mitra brand akan lebih yakin menggunakan kain premium karena lebih yakin terjual. Namun apabila potongan terlihat biasa-biasa saja, mitra brand kemungkinan akan menggunakan kain biasa pula. Pakaian dengan pola kompleks bisa menggunakan kain biasa karena nilai tambah dari pakaian itu terletak pada rumitnya pola. Pakaian dengan pola sederhana bisa menggunakan kain premium karena nilai tambah dari pakaian itu terletak pada kualitas bahan.

\section{KESIMPULAN}

Dari periode ini, mitra PkM bisa melihat bahwa proses membuat hingga menjual 1 baju membutuhkan proses yang panjang. Proses dari pola ke produk jadi melewati banyak revisi dan penyesuaian. Perlu pula adanya contoh kain yang dimiliki mitra brand agar pembuatan pola bisa sesuai dengan karakter kain. Foto katalog pun harus dicermati agar model mengenakan pakaian sesuai dengan desainnya (berhubung model baju sekarang semakin inovatif, terkadang model bisa bingung akan cara pakainya). Setelah memiliki foto katalog pun produk belum bisa dijual karena butuh diunggah ke channel penjualan yang sesuai beserta semua kontennya. Periode ini lebih memberikan insight kepada mitra PkM mengenai cara kerja industri baju secara lebih komprehensif.

\section{UCAPAN TERIMAKASIH}

Ucapan terimakasih disampaikan kepada LPPPM UPH yang telah memberikan kontribusi dalam pelaksanaan kegiatan dengan nomor kegiatan $\mathrm{PM}-001 / \mathrm{SoD} / \mathrm{I} / 2020$

\section{REFERENSI}

Data internal Zalora Indonesia, 2019

Data internal Lovadova, 2019-2020

Bobobobo. "Instagram Bobobobo". Internet: https://instagram.com/_bobobobo_?igshid=tkfq020 xe1kg, diakses pada September 2020

Lovadova. "Instagram Lovadova Indonesia". Internet:

https://instagram.com/lovadova_?igshid=znalvvhr5 594, diakses pada September 2020

Lovebonito. "Instagram Love Bonito Indonesia". Internet:

https://instagram.com/lovebonitoid?igshid=xuknzicj yzhs, diakses pada September 2020

Pomelo. "Instagram Pomelo Fashion". Internet: https://instagram.com/pomelofashion?igshid=fludk

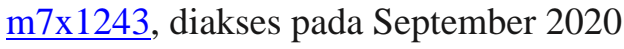

Shopfru. "Instagram Shopfru". Internet: https://instagram.com/shopfru?igshid=1feu8r93vcy gl, diakses pada September 2020

Zalora. "Instagram Zalora Indonesia". Internet: https://instagram.com/zaloraid?igshid=185vunra3q2 $\underline{2 \mathrm{u}}$, diakses pada September 2020 